of the skin is a mandatory part of any general medical checkup.

Malignant melanoma is much more common in whites living in sunny climates such as Australia, South Africa, and parts of the United States. The hazards of ultraviolet light irradiation and the occurrence of malignant disease of the skin have become common public knowledge in these areas. In Britain the popular misconception is that there is not enough irradiation to result in any important degree of skin damage. This is not so, and, furthermore, many people also take holidays abroad. Though ultraviolet light is not the sole cause of malignant melanoma, excessive exposure is an important factor in its pathogenesis, particularly in people whose skin has a tendency to go red whether or not it subsequently tans. The prophylactic use of sunscreening agents should be a routine for such people.

ANTHONY DU VIVIER

Consultant Dermatologist,

King's College Hospital,

London SE5 9RS

${ }^{1}$ Silverberg E. Cancer statistics, 1979. CA 1979;29:6-21.

2 Sober AJ, Fitzpatrick TB, Mihm MC Jr. Primary melanoma of the skin: recognition and management. 7 Am Acad Dermatol 1980;2:179-97.

${ }^{3}$ Clark WH Jr, Goldman LI, Mastrangelo M. Human malignant melanoma. New York: Grune and Stratton, 1979.

\section{The child who is slow to talk}

Delay in speech and language development is the most common developmental problem in young children. Martin Bax recently voiced concern that referral for expert help is often delayed because of a belief that the problem is trivial-the child will "grow out of it." This belief has some basis in fact, because most children who are delayed in speech development will eventually talk normally.

There are, however, several reasons why these children deserve attention and concern. Firstly, delay in speech may be a sign of an underlying condition such as deafness which requires diagnosis and treatment. Secondly, lack of "inner language" and of communication is a disadvantage to the child's development and learning and commonly leads to emotional or behavioural disturbance. Thirdly, the child's problems are not always over when he has developed satisfactory speech, because there is a strong association between early speech delay and later difficulties at school, particularly in reading, writing, and spelling. Finally, there is convincing evidence that skilled intervention can accelerate speech and language development in these children. ${ }^{2}$

When should the primary care doctor (general practitioner or clinical medical officer) refer the child, and to whom? The indications for concern must be based on knowledge of the normal pattern of speech development and its wide variations. The Newcastle study showed that half of all children are using words with meaning by $12 \frac{1}{2}$ months and $97 \%$ by 21 months. ${ }^{3}$ Half of all children join words into simple sentences by 23 months and $97 \%$ by 3 years. (For both milestones, girls are slightly more advanced than boys.) So, following the common rule of paying special attention to those who deviate from the population mean by more than two standard deviations, or to the most disadvantaged $3 \%$ of the population, we would be concerned about the child who is not using words with meaning by 21 months or constructing simple sentences by 3 years. If we add the child whose speech is still very difficult to understand at 4 years (because of poor articulation or omission or substitution of consonants), we have an easily remembered guide for the primary care doctor on when he should refer the child.

When, however, we are dealing with a process as complex as language development rules of thumb need to be interpreted with caution and thought. The line which separates the slowest $3 \%$ of the population in talking from the remainder is an arbitrary cut-off point; and it is arguable that the slowest talking $5 \%$ or even $10 \%$ of children are sufficiently disadvantaged to need help. The primary care doctor must strike a balance between the risks on the one hand of neglecting the child who would benefit from help and on the other of causing undue concern to parents or overloading the very stretched services to the detriment of the children who most need help. Another criticism of the simple rules is that they are entirely concerned with expressive speech and not with understanding. Understanding is of great importance but is less easily categorised into readily defined milestones. It can be measured quantitatively and very accurately by using Dr Joan Reynell's Developmental Language Scales ${ }^{4}$ or Mary Sheridan's miniature toy tests, ${ }^{5}$ but the use of these requires training and time and the general practitioner will usually have to rely on the history, supplemented by his own observations. He should be concerned about the child who is not understanding simple commands by 18 months. He should be wary of the child whose parents say he understands "no," which often means the child understands the tone of voice but has no true verbal understanding. Finally, while paying attention to the simple rules suggested, the primary care doctor should give due weight to parental concern about speech development. Though concern may sometimes indicate over-anxiety, it is often soundly based-the parents observe the child over a far longer period than the doctor. Furthermore, they may be aware of a familial tendency to language delay-Sonksen, ${ }^{6}$ for example, found speech delay in one in five of the siblings of children with specific disorders of language development.

The referral should in the first instance be to a paediatrician, not directly to a speech therapist. The speech therapist will take an important part in the assessment of the childanalysing the language development and the nature of the problem-and will probably play the major part in management. Nevertheless, the initial need is for diagnosis, and this is a paediatric responsibility requiring assessment of the child as a whole. The ideal referral is to a child development centre, where a paediatrician, speech therapist, audiologist, and psychologist (among others) work closely together.

Delayed speech development is much commoner in boys than in girls. Some indication of the relative frequency of causes of speech delay requiring specialist referral comes from our experience at the Newcomen Child Development Centre at Guy's Hospital. Among 122 children referred in one year with problems of speech or language the main cause was mental retardation in 37, specific disorders of language development in 30 , environmental factors including understimulation in 29 , and impaired hearing in 20 . Less common were structural abnormalities of the lips, tongue, or palate (three), motor disorders such as cerebral palsy (two), and autism (one). A quarter of the children had another contributory cause-usually impaired hearing or environmental factors-emphasising the need for comprehensive assessment.

Management depends on the cause, but in each of the major 
diagnostic groups intervention is of real value. Impaired hearing is the cause most obviously requiring early recognition and expert treatment, but in the other groups speech therapy, nursery or nursery-school placement, and advice and support to the parents will often greatly improve language development and family morale, and they appear to be more effective if started early. Bax's plea for care and attention for the child with delayed speech is entirely correct.

\section{R J RoBINSON}

Professor of Paediatrics,

Guy's Hospital Medical School,

London SE1 9RT

${ }^{1}$ Bax M. Communication disorders. Develop Med Child Neurol $1982 ; 24$ : 139-40.

2 Cooper J, Moodley M, Reynell J. The developmental language programme. Results from a five year study. Br F Disord Commun 1979;14:57-69.

${ }^{3}$ Neligan G, Prudham D. Norms for four standard developmental milestones by sex, social class and place in family. Develop Med Child Neurol $1969 ; 11: 413-22$.

4 Reynell J. Reynell Developmental Language Scales. Revised edition. Windsor: NFER Publishing Co, 1977.

5 Sheridan MD. Playthings in the development of language. Health Trends $1969 ; 1: 7-10$.

${ }^{6}$ Sonksen PM. MD thesis. The neuro-developmental and paediatric findings associated with significant disabilities of language development in pre-school children. University of London, 1979.

\section{Auditing the NHS}

The National Health Service faces the prospect of stringency compounded by uncertainty for the foreseeable future. Both the stringency and the uncertainty are documented in the latest report from the House of Commons Social Services Committee in its annual review of the Government's expenditure plans. ${ }^{1}$ The figures given in the Government's expenditure White Paper, ${ }^{2}$ published in March, implied a $2.5 \%$ growth in NHS services during 1982-3, of which $0.4 \%$ was to be financed by "efficiency savings." For the two following years the plans implied an annual growth in services of $0.5 \%$, to be wholly financed out of "efficiency savings." But the expenditure plans were out of date almost as soon as they were published. The assumptions about likely pay rises, built into the cash limits formula, proved overoptimistic. By the time the Social Services Committee published its report it was clear that the real growth in the current financial year would be less than $2 \%$-assuming that there are no further increases in pay and that the "efficiency savings" do not turn out to be a figment of ministerial imagination. Furthermore, the achievement of even a modest $0.5 \%$ growth in services in the subsequent two years depends not only on making the required "efficiency savings" but also on a continuing fall in the rate of salary and wage settlements, as envisaged in the Government's cash planning assumptions. So the only certainty would seem to be that the outlook is bleak.

But there is one fundamental problem about interpreting the Government's expenditure plans. This derives, as the Social Services Committee has argued in a series of reports over the years, ${ }^{34}$ from the conventional assumption that the output of the NHS may be equated with the inputs-that is, that spending figures are an adequate proxy for measuring the services provided. It is all too easy to fall into the trap of assuming that extra resources improve the NHS's performance and, conversely, that any cuts automatically imply deteriorating services and standards. The equation is far more complex. On the one hand, demands on the NHS are increasing in line with demographic and other changes. For example, the DHSS reckons that demographic factors-for example, an aging population-increase the demand for health services by $0.6 \%$. On the other hand, the capacity of the NHS to meet any given volume of demand depends not only on the quantity of resources available but, self-evidently, on the way in which they. are used. Few people in the NHS would contest the proposition that there is scope for improving the efficiency with which resources are used, though there is invariably sharp disagreement about whose efficiency should be improved. Clinicians emphasise the scope for making savings in managerial costs while administrators emphasise the scope for savings in clinical costs. On the face of it, therefore, the Government's contention that "efficiency savings" can pay for growth in services is reasonable.

The real difficulty lies in finding measures of NHS performance independent of the spending figures. Do "efficiency savings" mean that the same quantity and quality of services are being provided with fewer resources? Or do they mean that money has been saved by reducing the standards and scope of the services being provided? Does the decline in the growth rate of the NHS's budget-a growth rate which, in any case, only reflected a series of ministerial rule-of-thumb decisions about what was affordable-inevitably mean a deterioration in services? Or is it compatible with maintaining the level and quality of provision? None of these questions can be answered without information about change over time in the NHS's capacity for delivering care to patients-some way of relating input to output.

Already in 1980, therefore, the Social Services Committee argued that "the DHSS should give high priority to developing a comprehensive information system that would permit this committee and the public to assess the effect of changes in expenditure levels or patterns on the quality and scope of the services provided." 3 It returned to the same theme in 1981, when it was also taken up by the Committee of Public Accounts. The latter argued for the development of an information system that would permit the DHSS "to monitor key indicators of performance by the regions." 5 And it returned to the charge in its latest report, ${ }^{6}$ published earlier this year, when once again it emphasised the need for "effective monitoring" by the DHSS.

Parliamentary nagging has had its effect, as the DHSS's evidence to the two committees in 1982 shows. Despite the rhetoric of decentralisation that preceded the 1982 NHS reorganisation, the DHSS is in the process of strengthening central audit of the NHS. Starting this year each regional chairman and his officers have to account for their performance directly and personally to the Secretary of State while, in turn, each district chairman and his officers will have to account for their performance to the region. At the same time, the DHSS is developing new instruments for scrutinising the performance of the NHS. For example, it is launching an experimental management advisory service in several regions, designed to test different approaches to the problems of performance evaluation. It has also set up a working party to examine audit ( $\mathrm{p} 756$ ).

All this activity begs, however, a crucial question-what criteria are going to be used in measuring or auditing the performance of the NHS? The concept of performance is both complex and problematic. The NHS is a heterogeneous organisation pursuing various often ill-defined and sometimes 